\title{
RESENHA
}

dO1 https://doi.org/10.22481/praxisedu.v16i42.6456

\section{EDUCAÇÃO PÚBLICA DE QUALIDADE: UM OLHAR SOBRE OS EMBATES CONTEMPORÂNEOS DA JUVENTUDE}

\author{
PUBLIC QUALITY EDUCATION: A LOOK AT THE CONTEMPORARY FIGHTING OF \\ YOUTH
EDUCACIÓN DE CALIDAD PÚBLICA: UNA MIRADA A LA LUCHA CONTEMPORÁNEA DE LA JUVENTUD

Andréia Paula Basei

Universidade Estadual de Maringá - Brasil

Eduard Angelo Bendrath

Universidade Estadual de Maringá - Brasil

Resumo: Esta é uma resenha do livro "Participação e democracia no Brasil: da década de 1960 aos impactos pós-junho de 2013" publicado pela professora e pesquisadora Maria da Glória Gohn.

Palavras chave: Democracia. Juventude. Participação.

\begin{abstract}
This is a review of the book "Participação e democracia no Brasil: da década de 1960 aos impactos pós-junho de 2013" published by professor and researcher Maria da Glória Gohn.
\end{abstract}

Keywords: Democracy. Youth. Participation.

Resumen: Esta es una reseña sobre el libro "Participação e democracia no Brasil: da década de 1960 aos impactos pós-junho de 2013" publicado por la profesora e investigadora Maria da Glória Gohn

Palabras clave: Democracia. Juventud. Participación.

Maria da Glória Gohn, professora da Faculdade de Educação da Unicamp e visitante sênior na Universidade Federal do ABC, se dedica ao estudo e pesquisa dos movimentos sociais desde os anos de 1970, apresentando sempre dados atuais, contextualizados e ponderações incisivas sobre a temática. Uma das pesquisadoras mais experientes na temática movimentos sociais e participação sociopolítica na atualidade, nos apresenta subsídios para a compreensão da realidade atual a partir das bases e fundamentos buscados em seu campo de 
estudos e para defender a sua principal proposição relacionada à área educacional. Essencial e em momento muito propício e oportuno ela afirma: "A participação da sociedade civil nas lutas pela educação não é para substituir o Estado, mas para que este cumpra seu dever: o de propiciar educação de e com qualidade para todos. E esta é a pauta dos jovens na atualidade educação com qualidade" (GOHN, 2019, p. 226).

Em "Participação e democracia no Brasil: da década de 1960 aos impactos pós-junho de 2013", Maria da Glória Gohn traz reflexões pautadas por décadas de experiência com pesquisa sobre fenômenos sociais e políticos. Apresenta ao leitor as mudanças na configuração da realidade brasileira a partir das manifestações de junho de 2013 e os impactos no contexto político, nos temas da agenda nacional, os atores em cena e na situação sócio econômica da grande maioria da população.

A obra está organizada em duas partes, divididas em seis capítulos que, de modo geral, tem por objetivo contribuir com o debate sobre os rumos da democracia brasileira a partir do mapeamento e análise de cenários e fatos da participação social nas últimas cinco décadas. $\mathrm{O}$ enfoque principal é no segmento da juventude, seu envolvimento em movimentos sociais e protestos em defesa da educação, no intuito de viabilizar a reflexão sobre o cenário político e social no país em 2018/2019.

Na primeira parte, dividida em três capítulos, são apresentados elementos históricos e um quadro teórico sobre participação e democracia. No primeiro capítulo é possível fazer uma incursão teórica pelo tema participação social e política, iniciando pelo resgate de conceitos e abordagens teóricas. A autora identifica, especialmente, a partir da bibliografia internacional e autores expoentes, dez abordagens sobre o tema participação, no qual centraliza toda a discussão teórica. As questões norteadoras referem-se as formas como a participação social tem sido abordada na literatura e como contribuem para a compreensão dos acontecimentos sociopolíticos, culturais e participativos nas últimas décadas no Brasil. De forma perspicaz, o capítulo é encerrado com a conclusão de que há sempre uma disputa de poder entre as narrativas de cada abordagem, que na sua essência não apresentam caminhos para uma agenda que indique formas de superar as desigualdades sociais, cujas possibilidades estão muito além de participar, ser incluído ou protestar.

No segundo capítulo, Gohn faz uma leitura do cenário da participação social e política no Brasil da década de 1960 a 2010, dividindo-o em quatro ciclos, isto é, em quatro períodos possíveis de observação de novas formas de ação caracterizadas por protestos, movimentos e lutas sociais e, formas de participação da sociedade civil. Os quatro ciclos são denominados e subdivididos em: $1^{\circ}$ ciclo (anos de 1960): da explosão do povo nas ruas à 
resistência à repressão; $2^{\circ}$ ciclo da participação (lutas e movimentos na década de 1970): a organização pelas bases; $3^{\circ}$ ciclo da participação na década de 1980: Diretas Já e o processo constituinte e $4^{\circ}$ ciclo de movimentos no Brasil: nova fase da participação institucionalizada ou cidadã pós-1988. Em cada um dos períodos são apresentados e discutidos os avanços e recuos da participação dos cidadãos na sociedade civil, enquanto aspectos fundamentais para compreender não somente os impactos da Constituição de 1988 na esfera pública, mas também as mudanças nas configurações do Estado e da sociedade após junho de 2013.

O terceiro capítulo da obra, "Participação e protestos nas ruas brasileiras: de junho de 2013 a junho de 2018" é tratado pela autora como aquele que contém as questões chave com relação aos objetivos do livro. Este período é caracterizado como o quinto ciclo de protestos no Brasil, o qual é subdividido em quatro momentos distintos: primeiro momento (junho de 2013): a força dos jovens nas ruas; segundo momento (2014): a criação de organizações movimentalistas/contracorrentes nas ruas; terceiro momento (2015-2016): a multidão retorna as ruas e; quarto momento (2017-2018): novas alterações no cenário das ruas - redesenho das articulações. Estes momentos são abordados a partir da caracterização dos atores em cena, das formas de organização, dos repertórios de ação social e política, das estratégias de mobilização e das demandas. Nesse processo de construção histórica, social, política e cultural, Gohn mapeou, registrou, deu clareza e profundidade a trajetória desse fervor pela democracia, pela cidadania e contra as desigualdades sociais. As diversas faces das manifestações examinadas se apresentam dentro de uma dinâmica comum, de que democracia é um processo em permanente construção e as manifestações contribuíram para alterar a cultura política da sociedade, refletindo em efeitos e consequências contraditórias para os rumos da democracia. Neste cenário, as análises apresentadas nos auxiliam a identificar os aspectos que embasam as afirmações de que a democracia está sendo tensionada.

A segunda parte do livro, intitulada "Participação, juventude e educação", também formada por três capítulos, traz um enfoque analítico sobre os jovens e a educação frente aos movimentos, protestos e lutas pela democracia e pelos direitos a educação de qualidade. A juventude é tratada como um setor fundamental da sociedade brasileira a partir de 2013.

No capítulo quatro, "Jovens na política na atualidade: uma nova cultura política da participação", Gohn, adentra nas reflexões sobre a participação sociopolítica e cultural dos jovens. Inicialmente sustentadas nos conceitos sobre jovens e juventude, estudados a partir de diferentes papéis sociais, para na sequência, tecer suas considerações sobre participação e políticas públicas na juventude. Ela conclui, defendendo a importância de ampliar os estudos 
sobre as redes e mídias sociais e da cultura digital como possibilidade para a compreensão da cultura política e da nova cidadania que se desenha entre os jovens.

No seguimento da obra, o objetivo no capítulo cinco se volta para uma análise das lutas pela educação no Brasil. A partir de perspectivas históricas e recentes é posto em evidencia o envolvimento dos jovens em protestos e ocupações de escolas públicas que foram o centro de inúmeras reformas a partir de 2013. Para entender estes movimentos no campo da educação, Gohn, entende que as lutas pela educação envolvem a luta por direitos e são parte da construção da cidadania. Ela destaca alguns fatos no âmbito educacional anteriores a década de 1960, porém, demonstra um engajamento maior em apresentar um panorama das lutas e organizações nas décadas posteriores, seguindo o recorte temporal abordado na obra. Esta parte é finalizada com apontamentos de que as lutas e movimentos pela educação ganharam visibilidade tardia, alcançando a maioria da população recentemente, quando passa a ser vislumbrada como um espaço civilizatório, além de expressar um sucesso relativo de inclusão de cidadãos no mundo escolar, em escolas técnicas e em programas de universidades.

Diante do cenário descrito, a autora chama a atenção para o fato de que as lutas pela educação dizem respeito a toda a sociedade, ao poder público e ao modelo econômico vigente e correlaciona todos estes âmbitos ao destacar que as demandas são históricas e acompanharam o processo e o modelo de desenvolvimento do país.

Com "Maio de 1968 a maio de 2018: 50 anos de lutas sociais no Brasil", Gohn conclui o elenco de capítulos da obra. O objetivo da autora é apresentar os fatos que tornaram 1968 um marco histórico relevante e com impactos nas cinco décadas subsequentes. A juventude é destacada como os atores em cena pelas mudanças da sociedade, sobretudo, no que tange as questões da participação, dos direitos e da cultura política.

Dadas todas as análises, as considerações finais são iniciadas por um provocativo questionamento: "Para onde segue a democracia no Brasil?". Retomando alguns pontos da discussão, a autora ressalta que as manifestações e protestos a partir de 2013 deixaram explícitos diferentes modelos de participação e de movimentos sociais na atualidade, com identidades, propostas e perfis político e ideológico diversos. Além disso, vários elementos apontados ajudam a compreender a premissa inicial de que a democracia está sendo tensionada, as razões pelas quais ela se fortaleceu entre 1988 e 2013 e, aquelas responsáveis pelas restrições a partir de 2014, caracterizando um processo denominado de desdemocratização. A resposta para o questionamento inicial não está dada, entretanto, Gohn sinaliza que o caminho é em direção a algo novo, cujos resultados são imprevisíveis e dependentes do comportamento dos diferentes atores políticos em cena. 
De toda forma, é preciso destacar a brilhante análise de Gohn acerca das manifestações recentes no Brasil e o impacto na democracia e na participação social. Destacamos em especial, a articulação dos acontecimentos partindo de uma perspectiva histórica e conceitual da democracia e da participação, de conhecimentos em nível teórico mais amplos que permitem compreender as manifestações e os atores em cena, bem como o tensionamento da democracia marcado tanto pela ampliação da cidadania, quanto pela fragilidade do processo no contexto atual. Nesta publicação, há outro mérito da autora: seguir uma trilha de análises resgatando a esperança, o diálogo e o debate para revitalizar a democracia como método legítimo de expressão da vontade coletiva.

Vale uma incursão pela obra pelas oportunas contribuições para o aprofundamento das reflexões daqueles que estudam a educação contemporânea, em especial sua relação com o contexto social, político e econômico, com os movimentos sociais e as lutas pela democracia. É indicação de referencial, principalmente para aqueles que se preocupam com o direito a uma educação pública de qualidade, que acreditam que o mundo pode ser mais justo e que isso depende de uma sociedade com mais acesso à educação e mais recursos para as políticas educacionais.

\section{REFERÊNCIA}

GOHN, Maria da Glória. Participação e democracia no Brasil: da década de 1960 aos impactos pós-junho de 2013. Petrópolis, RJ: Vozes, 2019. 294 p.

\section{SOBRE OS AUTORES:}

\section{Andréia Paula Basei}

Doutoranda em Educação pela Universidade Estadual de Campinas (UNICAMP). Professora da Universidade Estadual de Maringá (UEM). Grupo de Pesquisa e Estudos em Políticas de Educação Física e Esportes (GEPEFE). E-mail: andreiabasei@yahoo.com.br (iD http://orcid.org/0000-0002-6675-6076

\section{Eduard Angelo Bendrath}

Doutor em Educação pela Universidade Estadual Paulista Júlio de Mesquista Filho (UNESP). Professor da Universidade Estadual de Maringá (UEM). Professor do Programa de Pós Graduação em Educação Física - Mestrado Profissional (Rede) UEM/UNESP. Grupo de Pesquisa e Estudos em Políticas de Educação Física e Esportes (GEPEFE). E-mail: bendrath@gmail.com

iD http://orcid.org/0000-0003-2980-4961 